\title{
Una visión ponderada de la legislación laboral: comentarios al régimen MYPE y a la propues- ta de «Ley de la Nueva Empresa»*
}

\section{A weighted view of labor law: commentaries on the MSE regime and the proposal «Law of New Enterprise»}

\section{CHRISTIAN SÁNCHEZ}

Resumen: El presente artículo evalúa el carácter constitucional del Régimen de la Micro y Pequeña Empresa (MYPE) y de la propuesta legislativa de la «Ley de la Nueva Empresa» a partir de la jurisprudencia del Tribunal Constitucional. Con dicho propósito parte de analizar los caracteres propios del derecho a la igualdad, que como derecho liberal clásico es base de derechos sociales como el derecho al trabajo. Finalmente, el artículo busca despejar la duda de si los referidos regímenes, MYPE y Ley de la Nueva Empresa, obedecen a una política de promoción del empleo o más bien introducen un trato diferenciado sin sustento objetivo y, en consecuencia, inconstitucional.

Palabras clave: Ley de Nueva Empresa - regímenes laborales - derechos fundamentales laborales - principio - derecho a la igualdad

Summary: The present article evaluates constitutional character of the regime of Micro and Small Enterprises (MSE) and the legislative proposal of «Law of New Enterprise» from the jurisprudence of the Constitutional Court. With this purpose it starts with analyzing own characters of the right to equality as a classical liberal right that is based on social rights as the right to work. Finally, the article seeks to dispel doubt of whether those regimes, MSE and the Law of New Enterprise, they obey to a policy of promotion of employment or rather they introduce a differentiated treatment without objective basis and therefore unconstitutional.

Keywords: Law of New Company - labor regimes - fundamental labor rights - principle - right to equality

CONTENIDO: INTRODUCCIÓN.- I.- REGÍMENES LABORALES ESPECIALES, EL PRINCIPIO-DERECHO A LA IGUALDAD Y LA PONDERACIÓN DE PRINCIPIOS.II. EL ENFOQUE PREDOMINANTE EN LA FORMALIZACIÓN LABORAL DE LOS TRABAJADORES DE LA MICROEMPRESA: LA REDUCCIÓN DE COSTOS LABORALES.- III. EL RÉGIMEN DE LA LEY MYPE Y LA AFECTACIÓN A DERECHOS FUNDAMENTALES LABORALES Y DE PROTECCIÓN SOCIAL.IV. ANÁLISIS DEL RÉGIMEN LABORAL DE LA "NUEVA EMPRESA».IV.1. PERMANENCIA EN EL RÉGIMEN.- IV.2. BENEFICIOS SOCIALES EN LA NUEVA EMPRESA.- V. COMENTARIO.- VI. CONCLUSIONES.

\footnotetext{
* Agradezco a Willman Meléndez por sus valiosos comentarios y reflexiones que contribuyeron a la versión final de este artículo.

** Profesor de la Facultad de Derecho de la Pontificia Universidad Católica del Perú.
} 
[...] la ley ha dejado de ser la única, suprema y racional fuente del Derecho que pretendió ser en otra época, y tal vez este sea el sintoma más visible de la crisis de la teoría del derecho positivista, forjada en torno a los dogmas de la estatalidad y de la legalidad del Derecho.

LUIS PRIETO SANCHÍS, Neoconstitucionalismo y ponderación judicial

\section{INTRODUCCIÓN}

Conforme a lo señalado por el Tribunal Constitucional, nuestra Constitución declara que nuestro Estado encarna el modelo «democrático y social de derecho», a partir de una interpretación conjunta de sus artículos 3 y 43.

Este modelo de Estado requiere, según el mismo tribunal, de dos requisitos básicos: i) la existencia de «condiciones materiales» para alcanzar sus presupuestos y ii) la identificación del Estado con los fines de su «contenido social». Precisamente, los fines de su denominado «contenido social» no son más que el logro de la plena efectividad de todos los derechos fundamentales, incluidos por cierto los derechos económicos, sociales y culturales. Para ello, dentro del mismo modelo de Estado «democrático y social de derecho» se requiere de

[...] una decidida labor del Estado, por un lado orientada a «realizar acciones» que garanticen un efectivo disfrute de derechos tales como la libertad, seguridad, propiedad (por ejemplo, optimizando los servicios de seguridad, la función jurisdiccional o los registros de propiedad), salud, trabajo y educación (por ejemplo, mejorando los servicios de salud, creando más puestos de trabajo y eliminando el analfabetismo), entre otros; y por otro a «abstenerse» de afectar tales derechos (por ejemplo, no interferir irrazonable y desproporcionadamente en la libertad o propiedad, o no afectar o perjudicar los servicios educativos y de salud existentes) ${ }^{1}$.

Pero el Tribunal Constitucional también ha dejado sentado que el modelo de Estado se define como uno «constitucional de derecho»; ello a partir de una interpretación sistemática de lo dispuesto en los artículos 38, 45 y 31 de la Constitución ${ }^{2}$. Con ello, el tribunal reafirma el tránsito de la

1 Sentencia del Tribunal Constitucional (TC) recaída en el expediente 4232-2004-AA/TC. Así, en dicha sentencia, el TC señala que dentro de los fines de contenido social que identifican a este modelo del Estado se encuentran, por ejemplo, el derecho a la salud, el derecho al trabajo y el derecho a la educación, por lo que para lograr la mayor efectividad de estos, tal como se ha mencionado en los parágrafos precedentes, el Estado tiene tanto «obligaciones de hacer» (realizar acciones que tiendan al logro de un mayor disfrute del derecho) como «obligaciones de no hacer» (abstenerse de interferir en el ejercicio de los derechos), por lo que no resultan válidas las posiciones que solo ven en los derechos civiles y políticos (libertad, seguridad y propiedad, entre otros) obligaciones estatales de no hacer, y en los derechos sociales (salud, trabajo, educación) solo obligaciones estatales de hacer.

2 Sentencia del TC recaída en el expediente 5854-2005-PA/TC: «2. La Constitución como norma jurídica. 3. El tránsito del Estado Legal de Derecho al Estado Constitucional de Derecho supuso, entre otras cosas, abandonar la tesis según la cual la Constitución no era más que una mera norma política, esto es, una norma carente de contenido jurídico vinculante y compuesta únicamente por una serie de disposiciones orientadoras de la labor de los poderes públicos, para consolidar la doctrina conforme a la cual la Constitución es también una Norma Jurídica, es decir, una norma con contenido 
disciplina jurídica de lo que se denomina paleo-iuspositivismo del Estado legislativo de Derecho o Estado legal a un modelo neo-iuspositivista del Estado constitucional de Derecho o Estado constitucional, donde no solo en la forma se busque la primacía constitucional por sobre la literalidad de las normas inferiores en jerarquía; sino que ello - yendo más allá de la simple declaración - se irradie en la práctica que del Derecho hagan los operadores jurídicos, sean estos jueces, funcionarios y/o servidores públicos y defensores en general ${ }^{3}$.

Dicho modelo, nos referimos al modelo del «Estado constitucional y social de Derecho», se inserta dentro del modelo de Estado delineado por una «presuntamente nueva cultura jurídica» - para utilizar la denominación empleada por Prieto Sanchís- conocida como neoconstitucionalismo, constitucionalismo contemporáneo o «constitucionalismo a secas», que ejerce una poderosa influencia, como señala el autor, en la configuración de un nuevo modelo o forma de organización jurídica política, una nueva teoría del derecho que trata de explicar aquel y una ideología que justifica y trata de defender aquella forma de organización jurídico-política ${ }^{4}$.

Pues bien, no cabe duda que el Tribunal Constitucional ha definido el derrotero que debe seguir nuestra cultura jurídica y con ello la «nueva» teoría del derecho que por cierto debe también servir de marco de referencia del Derecho del Trabajo.

En palabras de Prieto Sanchís, la nueva teoría del Derecho puede definirse con los siguientes cinco rasgos:

[...] más principios que reglas, más ponderación que subsunción; omnipresencia de la constitución en todas las áreas jurídicas y en todos

dispositivo capaz de vincular a todo poder (público o privado) y a la sociedad en su conjunto. Es decir, significó superar la concepción de una pretendida soberanía parlamentaria, que consideraba a la ley como la máxima norma jurídica del ordenamiento, para dar paso — de la mano del principio político de soberanía popular- al principio jurídico de supremacía constitucional, conforme al cual, una vez expresada la voluntad del Poder Constituyente con la creación de la Constitución del Estado, en el orden formal y sustantivo presidido por ella no existen soberanos, poderes absolutos o autarquías. Todo poder devino entonces en un poder constituido por la Constitución y, por consiguiente, limitado e informado, siempre y en todos los casos, por su contenido jurídico-normativo".

3 Consecuentemente: i) cambian las condiciones de validez de las leyes, dependientes ya no solo de la forma de su producción sino también de la coherencia de sus contenidos con los principios constitucionales; ii) se disciplinan las formas de producción legislativa, imponiendo prohibiciones y obligaciones de contenido, correlativas unas a los derechos de libertad y las otras a los derechos sociales, cuya violación genera antinomias o lagunas que la ciencia jurídica tiene el deber de constar para que sean eliminadas o corregidas; iii) se altera el papel de la jurisdicción, aplicándose la ley solo si es constitucionalmente válida, siendo su aplicación e interpretación un juicio sobre la ley misma que el juez tiene el deber de censurar como inválida mediante la denuncia de su inconstitucionalidad, cuando no sea posible interpretarla en sentido constitucional; iv) se introduce una dimensión sustancial en la naturaleza de la democracia que la limita y complementa a la vez. Lo primero en tanto que introduce prohibiciones y obligaciones a los poderes de la mayoría que de otro modo serían absolutos. Lo segundo, en tanto que tales prohibiciones y obligaciones se configuran como garantías de los derechos de todos frente a los abusos de dichos poderes. Al respecto, ver FERRAJOLI, Luigi. «Pasado y futuro del Estado de derecho». En CARBONELL, Miguel (ed.). Neoconstitucionalismo(s). Madrid: Trotta, 2003, pp. 18-19.

4 PRIETO SANChís, Luis. «Neoconstitucionalismo y ponderación judicial». En CARBonelL, Miguel (ed.). Ob. cit., p. 123. 
los conflictos mínimamente relevantes, en lugar de espacios exentos en favor de la opción legislativa o reglamentaria; omnipotencia judicial en lugar de autonomía del legislador ordinario; y, por último, coexistencia de una constelación plural de valores, a veces tendencialmente contradictorios, en lugar de homogeneidad ideológica en torno a un puñado de principios coherentes entre sí y en torno, sobre todo, a las sucesivas opciones legislativas ${ }^{5}$.

Consecuentemente, la ponderación juega un papel central en esta nueva versión de la teoría del derecho. Así, como método de argumentación ha sido víctima de muchas críticas debido principalmente al evidente uso de valoraciones (que abren campo a una amplia discrecionalidad); al incremento de la indeterminación del derecho por la utilización de principios; y a la evaluación de las «circunstancias del caso» que por su indeterminación plantean la utilización de «jerarquías móviles» que varían según la particularidad del caso haciendo que unos principios aparezcan derrotados, mientras que en otros casos que enfrentan los mismos principios, se produzca un resultado diferente; en fin, todas estas y otras tantas son las críticas que se formulan a este método argumentativo ${ }^{6}$.

Sin embargo, en su defensa se afirma que aun cuando «exista un cierto peligro de particularismo no significa que la ponderación abra las puertas a juicios basados en la intuición, el pálpito o las corazonadas»? pues como bien señala Sanchís y con quien coincide Atienza, se trata de aplicar con seriedad las exigencias de la argumentación, lo cual requiere de «motivar y razonar» en función a las más importantes propiedades relevantes de un caso para llegar a la construcción de verdaderas reglas para resolver casos futuros dotando así de universalidad los resultados provenientes de la ponderación.

En resumen, ni este método ni sus resultados deben estar privados de racionalidad (racionalidad práctica), manteniendo las decisiones que emanen de él «entre sí un considerable grado de coherencia» que se fundamenten en «criterios que pretenden ser universales» y que produzcan «consecuencias socialmente aceptables» sin contradecir ningún extremo constitucional como bien señala Atienza.

Pues bien, no cabe duda que el Tribunal Constitucional ha hecho uso de este método argumentativo con un rol protagónico en el nuevo paradigma de la teoría del derecho y ello queda demostrado en

5 L. cit.

6 Sobre los argumentos a favor y en contra de la ponderación y en especial sobre la defensa de esta, ver PRIETO SANCHÍS, Luis. «El juicio de ponderación constitucional». En CARBONELL, Miguel \& Pedro GRÁNDEZ CASTRO (coords.). El principio de proporcionalidad en el derecho contemporáneo. Lima: Palestra, 2010; ATIENZA, Manuel. «A Vueltas con la ponderación». La Razón del Derecho. Revista Interdisciplinaria de Ciencias Jurídicas, 1 (2010).

7 Prieto Sanchís, Luis. «El juicio de ponderación constitucional». p. 105. 
innumerables sentencias en las que ha recurrido a él para resolver un conflicto entre principios.

Lamentablemente, en lo que atañe a casos vinculados al derecho del trabajo, como es el caso de la sentencia recaída en el expediente 00027-2006-PI, en la que se tratan de ponderar principios en pugna vinculados a los efectos de políticas de «fomento del empleo» en un determinado sector productivo, el alto tribunal no tomó en consideración todas las propiedades relevantes del caso para resolverlo adecuadamente conforme a la Constitución.

Desde nuestro punto de vista, las propiedades relevantes de un caso como el que a continuación analizaremos exigen ir más allá de los argumentos jurídicos y acercarnos a otras disciplinas como la economía del trabajo para obtener suficientes datos de la realidad que nos permitan comprender, en su real magnitud, los efectos que pueden generar este tipo de políticas. Cabe también realizar a futuro una reflexión profunda sobre la base del nuevo paradigma que el alto tribunal defiende acerca de las instituciones del derecho del trabajo, materia que obviamente escapa al presente artículo.

En este escenario, el presente artículo evalúa el carácter constitucional del régimen de la micro y pequeña empresa (MYPE) y de la propuesta legislativa de la «Ley de la Nueva Empresa».

A tal fin, iniciaremos el análisis asentando los caracteres propios del derecho a la igualdad que como derecho liberal clásico es base de derechos sociales como el derecho al trabajo.

Hecho ello, haremos hincapié en cada uno de los caracteres del régimen MYPE como de la «Ley de la Nueva Empresa» para poder determinar si su regulación es o no acorde al modelo constitucional de estado social de derecho, el cual no solo se debe limitar al reconocimiento del derecho al trabajo; sino que debe procurar el goce de los derechos sociales en condiciones equitativas para todos los ciudadanos y ajenas, evidentemente, a todo viso discriminatorio.

Se buscará determinar si los referidos regímenes, MYPE y Ley de la Nueva Empresa, obedecen a una política de promoción del empleo o más bien introducen un trato diferenciado sin sustento objetivo y en consecuencia, inconstitucional. 


\section{REGÍMENES LABORALES ESPECIALES, EL PRINCIPIO-DERECHO A LA IGUALDAD ${ }^{8}$ Y LA PONDERACIÓN DE PRINCIPIOS}

La jurisprudencia del Tribunal Constitucional ha puesto de relieve la necesidad de efectuar un

[...] adecuado discernimiento entre dos categorías jurídicoconstitucionales, a saber, diferenciación y discriminación. [...] la diferenciación está constitucionalmente admitida, atendiendo a que no todo trato desigual es discriminatorio; es decir, se estará frente a una diferenciación cuando el trato desigual se funde en causas objetivas y razonables. [...], cuando esa desigualdad de trato no sea ni razonable ni proporcional, estaremos frente a una discriminación y, por tanto, frente a una desigualdad de trato constitucionalmente intolerable?

A partir de lo señalado por el Tribunal, no todo trato diferenciado es discriminatorio pues allí donde hay elementos objetivos y razonables (diferencias) para distinguir o tratar de manera distinta no hay discriminación.

\section{Según Ferrajoli}

[...] las diferencias — sean naturales o culturales— no son otra cosa que los rasgos específicos que diferencian y al mismo tiempo individualizan a las personas y que, en cuanto tales, son tutelados por los derechos fundamentales. Las desigualdades — sean económicas o sociales— son en cambio las disparidades entre sujetos producidas por la diversidad de sus derechos patrimoniales, así como de sus posiciones de poder y sujeción. Las primeras concurren, en su conjunto, a formar las diversas y concretas identidades de cada persona; las segundas, a formar las diversas esferas jurídicas ${ }^{10}$.

De este modo, mientras las diferencias deben ser tuteladas y valorizadas por el principio de igualdad formal frente a discriminaciones o privilegios y como tales merecen una especial atención de parte del legislador para relevarlas; por otro lado, las desigualdades deberían ser removidas o al menos reducidas por la igualdad sustancial a la que apunta la garantía y ejercicio de los derechos fundamentales sociales.

Más aun, Ferrajoli conecta claramente el principio de igualdad con los derechos fundamentales de la persona: «[...] a los de libertad en cuanto

8 Sobre el particular, ver QUIÑONES, Sergio \& Christian SÁNCHEZ. «Igualdad ante la Ley y Regímenes Laborales Especiales". En SANGUINETI, Wilfredo \& otros. Estudios de derecho del trabajo y la seguridad social. Libro Homenaje a Javier Neves Mujica. Lima: Grijley, 2009, pp. 291-307.

9 Expediente 0048-2004-Al, fundamento 62.

10 FerRAJolı, Luigi. Derechos y garantías. La ley del más débil. Madrid: Trotta, 1999, p. 82. 
derechos al igual respeto de todas las "diferencias"; [y] a los sociales en cuanto derechos a la reducción de las "desigualdades" ${ }^{11}$.

En definitiva, cuando nos encontremos frente a diferencias, la igualdad ante la ley (desplegando su enfoque formal) debe garantizar su valoración y respeto, relevando dichas diferencias e introduciendo tratos diferenciados razonables y proporcionados. Cuando nos encontramos frente a desigualdades, en cambio, la igualdad ante la ley (desplegando su enfoque sustancial) debe apuntar a reducirlas o compensarlas, buscando eliminar las referidas desigualdades.

Nótese, pues, que identificar una situación de desigualdad y buscar su reducción, compensación y —eventualmente - su eliminación constituye la garantía esencial del principio de igualdad ante la ley desde su enfoque sustancial y se vincula íntimamente con el ejercicio efectivo de los derechos fundamentales de contenido social, dentro de los que destaca —naturalmente - el derecho al trabajo y el de la protección social.

De esta forma, las diferencias en el trabajo, esto es, las particularidades de la prestación de servicios son pues el primer sustento de un trato diferenciado en materia laboral que autoriza a un trato diferenciado legítimo, ejemplo de ello es el régimen especial de los trabajadores portuarios, el de construcción civil, entre otros ${ }^{12}$.

De otro lado, tenemos a los tratos diferenciados que tienen como sustento el rol estatal de promoción del empleo o de un determinado sector productivo que por sus características particulares (por sus diferencias objetivas en contraposición a otros sectores productivos) merece una política de promoción.

Según el artículo 23 de la Constitución, el Estado asume las siguientes responsabilidades con relación al trabajo: a) promover condiciones para el progreso social y económico, para tal efecto, tiene la obligación de

11 Ibídem, p. 83

12 Sobre el particular podemos reseñar: «En el empleo privado existen al menos 12 regulaciones diferenciadas según sector de actividad y oficio, y en el empleo público al menos 15 regulaciones diferenciadas también por sector de actividad. En ocasiones, las diferencias de trato obedecen a razones válidas como la eventualidad de la labor o la multiplicidad de empleadores (p.e. construcción), el régimen de apropiación de los frutos del trabajo (p.e. artistas) o la presencia de condiciones de trabajo diferenciadas, indispensables para la realización del contrato de trabajo (pe. labores mineras o vacaciones de docentes). Pero también, en otros casos, las diferencias legislativas van más allá de las particularidades propias de determinadas labores y se convierte en arbitrarias. Por ejemplo, la previsión de beneficios económicos recortados o la inaplicación de la remuneración mínima en el régimen del trabajo del hogar carecen de justificación objetiva y convierten la diferenciación en discriminatoria por el efecto adverso o negativo que su aplicación origina en las mujeres. Otras veces, como ya se ha adelantado, las diferenciaciones obedecen a supuestos fines promocionales como ocurre, principalmente, con la norma que establece el régimen de contratación temporal para las empresas que realizan exportaciones no tradicionales, las normas de promoción del sector agrario y el régimen de promoción y formalización de la micro y pequeña empresa" (GAMERO, Julio \& Edgardo BALBín. «Diagnóstico y agenda de los trabajadores para los candidatos presidenciales». Documento de Trabajo, mayo de 2011, p. 35).

UNA VISIÓN

PONDERADA DE

LA LEGISLACIÓN

LABORAL:

COMENTARIOS AL

RÉGIMEN MYPEY

A LA PROPUESTA

$D E \ll L E Y ~ D E L A$

NUEVA EMPRESA»

A WEIGHTED VIEW

OF LABOR LAW:

COMMENTARIES

ON THE MSE

REGIME AND

THE PROPOSAL

"LAW OF NEW

ENTERPRISE" 
establecer políticas de fomento del empleo productivo y de educación para el trabajo; b) asegurar que ninguna relación laboral limite el ejercicio de los derechos constitucionales ni desconozca o rebaje la dignidad del trabajador; c) asegurar que a ningún trabajador se le obligue a prestar servicios sin retribución compensatoria o sin su libre consentimiento; y d) proteger especialmente la actividad laboral de la madre, el menor de edad y el impedido.

El artículo 58 de la Constitución reconoce que la iniciativa privada se ejerce en el marco de una economía social de mercado ${ }^{13}$, y que en dicha economía el Estado orienta el desarrollo del país, y actúa principalmente en las áreas de promoción de empleo, salud, educación, seguridad, servicios públicos e infraestructura.

La economía social de mercado y la cláusula de Estado Social imprimen al Estado el deber de adoptar medidas legislativas que, además de fomentar la inversión privada, estén orientadas al cumplimiento de fines sociales de relevancia constitucional como son alcanzar una distribución equitativa del ingreso, la prestación eficaz, eficiente y plena de los servicios sociales, el efectivo goce de los derechos económicos y sociales consagrados en la Constitución y la verificación del principio de igualdad en lo atinente a la elaboración y aplicación de la ley; y, singularmente, en lo pertinente a la consolidación de la igualdad real de oportunidades.

En estos casos, en los que se pretende juzgar si un trato diferenciado es o no discriminatorio, o, de otro modo, si una política pública de fomento de la formalización del empleo (expresada a través de una norma con rango de ley) afecta de manera desproporcionada o irrazonable un conjunto de derechos fundamentales; se aprecia un conjunto de principios que juegan en sentido contrario u opuesto: de un lado, el deber estatal de promoción o fomento del empleo y, de otro, los derechos fundamentales laborales y de protección social.

Así pues, si bien el rol estatal de promotor del empleo encuentra acogida en nuestra constitución, ello no obsta que ninguna política de fomento del empleo puede afectar derechos fundamentales ${ }^{14}$ de

13 El TC ha señalado que: «[...] la economía social de mercado [...] trata de un modelo de economía de mercado que pone atención y preocupación en la corrección de desigualdades y en promover el desarrollo económico en un marco de justicia social [...]», añadiendo que «[...] la economía social de mercado es una condición importante del Estado social y democrático de Derecho. [...] debe ser ejercida con responsabilidad social y bajo el presupuesto de los valores constitucionales de la libertad y la justicia. A tal efecto está caracterizada [...] por los tres elementos siguientes: a) Bienestar social; lo que debe traducirse en empleos productivos, trabajo digno y reparto justo del ingreso. [...] b) Un Estado subsidiario y solidario, de manera tal que las acciones estatales directas aparezcan como auxiliares, complementarias y temporales. En suma, se trata de una economía que busque garantizar que la productividad individual sea, por contrapartida, sinónimo de progreso social» (expediente 00008-2003-Al/TC, fundamento 13 (a)).

14 Adoptamos la definición propuesta por el TC, según la cual, los derechos fundamentales son aquellos que la Constitución reconoce y que se derivan del principio-derecho de dignidad humana, 
manera desproporcionada o irrazonable, precisamente por el carácter fundamental y propiamente universal de los derechos fundamentales, en este caso, de los de naturaleza laboral y de protección social.

El instrumento utilizado por el Tribunal para determinar si un trato diferenciado es razonable y proporcional se ha denominado el test de igualdad (a partir de un ejercicio argumentativo que se realiza sobre tres sub principios: el de idoneidad o adecuación, el de necesidad y el de proporcionalidad), expresión metodológica de una técnica de argumentación jurídica que es la ponderación ${ }^{15}$.

En este caso, se hace necesaria una ponderación entre los diversos principios que entran en juego de manera conflictiva, ello nos lleva a señalar que siempre que una política pública de fomento del empleo desee introducir un trato diferenciado, se requiere un análisis detallado de los efectos de dicha política en los derechos fundamentales, en su temporalidad estricta, y en la necesaria introducción de equilibrios entre lo individual y lo colectivo.

El juicio de ponderación para este caso podría resumirse a partir de la siguiente regla: «es posible crear un régimen laboral especial de fomento a una determinada actividad siempre que el mismo sea temporal, esté sujeto a una evaluación constante de sus efectos en el mercado de trabajo y en las relaciones individuales y colectivas de trabajo y no afecte de manera desproporcionada o irrazonable derechos fundamentales».

no agotándose en los derechos calificados como fundamentales por la propia Constitución, sino que abarcan también bajo dicha categoría a otros derechos implícitos que se derivan de principios constitucionales básicos. Así, en la Sentencia del TC, recaída en el expediente 1417-2005-AA/TC, en el proceso constitucional de amparo seguido por Manuel Anicama Hernández, fundamentos jurídicos 2 al 4, dicho tribunal ha señalado: «§1. Los derechos fundamentales de la persona humana. 2. El concepto de derechos fundamentales comprende: «tanto los presupuestos éticos como los componentes jurídicos, significando la relevancia moral de una idea que compromete la dignidad humana y sus objetivos de autonomía moral, y también la relevancia jurídica que convierte a los derechos en norma básica material del Ordenamiento, y es instrumento necesario para que el individuo desarrolle en la sociedad todas sus potencialidades. Los derechos fundamentales expresan tanto una moralidad básica como una juridicidad básica». (PECES-BARBA, Gregorio. Curso de Derechos Fundamentales. Teoría General. Madrid: Universidad Carlos III de Madrid. Boletín Oficial del Estado, 1999, p. 37). Consecuentemente, si bien el reconocimiento positivo de los derechos fundamentales (comúnmente, en la Norma Fundamental de un ordenamiento) es presupuesto de su exigibilidad como límite al accionar del Estado y de los propios particulares, también lo es su connotación ética y axiológica, en tanto manifiestas concreciones positivas del principio-derecho de dignidad humana, preexistente al orden estatal y proyectado en él como fin supremo de la sociedad y del Estado (artículo 1ํ de la Constitución)».

15 Prieto Sanchís nos dice sobre aquellos supuestos en los que se recurre a la ponderación: «Los supuestos hasta aquí examinados se caracterizan, pues, por la existencia de un conflicto constitucional que no es posible resolver mediante el criterio de especialidad. El juez ante el caso concreto encuentra razones de sentido contradictorio; y es obvio que no cabe resolver el conflicto declarando la invalidez de algunas de esas razones, que son precisamente razones constitucionales, ni tampoco afirmando que algunas de ellas han de ceder siempre en presencia de su opuesta, pues ello implicaría establecer una jerarquía que no está en la Constitución. Tan solo cabe entonces formular un enunciado de preferencia condicionada, trazar una «jerarquía móvil» o «axiológica» y afirmar que en el caso concreto debe triunfar una de las razones en pugna, pero sin que ello implique que en otro no deba triunfar la contraria. La ponderación intenta ser un método para la fundamentación de ese enunciado de preferencia referido al caso concreto, un auxilio para resolver conflictos entre principios del mismo valor o jerarquía, [...]" (PRIETO SANCHís, Luis. "Neoconstitucionalismo y ponderación judicial», pp. 142-143). 
Una regla de esta naturaleza se hace necesaria en la futura Ley General de Trabajo para que sirva como guía u orientación para el legislador y para que postule de manera explícita la necesidad de ponderar siempre que se quiera introducir un trato diferenciado con efectos en derechos fundamentales. La creación de futuros regímenes laborales especiales no puede estar exenta de un juicio de ponderación.

\section{EL ENFOQUE PREDOMINANTE EN LA FORMALIZACIÓN LABORALDELOSTRABAJADORES DELAMICROEMPRESA: LA REDUCCIÓN DE COSTOS LABORALES}

Se constata que las políticas públicas de promoción del empleo en el sector de la microempresa han tenido como eje la de reducción de costos laborales, con directa incidencia en un conjunto de derechos laborales fundamentales y de protección social, reconocidos por la Constitución.

Como ejemplo, podemos apreciar en la siguiente tabla la notable reducción de los denominados «costos laborales» ${ }^{16}$ que ha operado con la entrada en vigencia del régimen de la Ley MYPE ${ }^{17}$ :

\begin{tabular}{|c|c|c|c|c|}
\hline Régimen laboral & General & Pequeña & Micro & Total \\
\hline \multicolumn{5}{|l|}{ Cobertura potencial } \\
\hline Empresa & $0,1 \%$ & $4,1 \%$ & $95,8 \%$ & $100 \%$ \\
\hline Trabajadores & $23,7 \%$ & $26,8 \%$ & $49,6 \%$ & $100 \%$ \\
\hline Remuneración mensual referencial & S/. 990 & & & \\
\hline $\begin{array}{l}\text { Costos laborales no salariales a cargo del empleador } \\
\text { (\% de la remuneración) }\end{array}$ & & & $5,7 \%$ & \\
\hline Compensación por tiempo de servicios (CTS) & $10,3 \%$ & $4,9 \%$ & - & \\
\hline Gratificaciones & $17,8 \%$ & $8,3 \%$ & - & \\
\hline Vacaciones & $8,9 \%$ & $4,2 \%$ & $4,2 \%$ & \\
\hline Salud & $11,1 \%$ & $9,8 \%$ & $1,5 \%$ & \\
\hline Asignación familiar & $6,8 \%$ & - & - & \\
\hline Seguro de vida & $0,7 \%$ & $0,6 \%$ & - & \\
\hline Seguro complementario de trabajo de riesgo & $1,5 \%$ & $1,3 \%$ & - & \\
\hline $\begin{array}{l}\text { Servicio Nacional de Adiestramiento en Trabajo } \\
\text { Industrial (SENATI) }\end{array}$ & $0,9 \%$ & - & - & \\
\hline
\end{tabular}

Elaboración: Fernando Cuadros

16 Estos pueden dividirse, en términos económicos, en: salariales (remuneración) y no salariales (compensación por tiempo de servicios, gratificaciones, remuneración vacacional, contribuciones a la seguridad social, asignación familiar, entre otros).

17 Nos referimos al Texto Único Ordenado de la Ley de Promoción de la Competitividad, Formalización y Desarrollo de la Micro y Pequeña Empresa y del Acceso al Empleo Decente, aprobado por decreto supremo 007-2008-TR. 
Cuáles han sido los resultados de esta política de formalización a través de la reducción de costos laborales, los podemos apreciar en el siguiente cuadro:

\begin{tabular}{|l|c|c|c|c|c|}
\hline & $\begin{array}{c}\text { Total } \\
\text { (formales e } \\
\text { informales) }\end{array}$ & $\begin{array}{c}\text { Formalización con ley } \\
28015\end{array}$ & $\begin{array}{c}\text { \% de } \\
\text { jul. 2003-sep. 2008 }\end{array}$ & $\begin{array}{c}\text { Formalizadas con nueva } \\
\text { formalizados }\end{array}$ & $\begin{array}{c}\% \text { de } \\
\text { Let. 2008-ago. 2011 }\end{array}$ \\
\hline $\begin{array}{l}\text { Micro- } \\
\text { empresas }\end{array}$ & 944900 & 44089 & $4,7 \%$ & 71564 & $7,6 \%$ \\
\hline $\begin{array}{l}\text { Pequeñas } \\
\text { empresas }\end{array}$ & 40375 & - & - & 9249 & $22,9 \%$ \\
\hline
\end{tabular}

\begin{tabular}{|l|c|c|c|}
\hline & $\begin{array}{c}\text { Total (formales } \\
\text { e informales) }\end{array}$ & $\begin{array}{c}\text { Formalizadas con la } \\
\text { Ley MYPE }\end{array}$ & $\begin{array}{c}\% \text { de } \\
\text { formalizados }\end{array}$ \\
\hline Trabajadores de microempresas & 2561734 & 185764 & $7,3 \%$ \\
\hline Trabajadores de pequeñas empresas & 1382156 & 49712 & $3,6 \%$ \\
\hline
\end{tabular}

\begin{tabular}{|l|c|}
\hline & $\begin{array}{c}\text { \% de empresas registros en } \\
\text { Planilla Electrónica Inscritas en REMYPE }\end{array}$ \\
\hline Microempresas & $26,4 \%$ \\
\hline Pequeñas Empresas & $16,8 \%$ \\
\hline
\end{tabular}

UNA VISIÓN

PONDERADA DE

LA LEGISLACIÓN

LABORAL:

COMENTARIOS AL

RÉGIMEN MYPE Y

A LA PROPUESTA

DE «LEY DE LA

NUEVA EMPRESA»

A WEIGHTED VIEW

OF LABOR LAW:

COMMENTARIES

ON THE MSE

REGIME AND

THE PROPOSAL

"LAW OF NEW

ENTERPRISE"

Fuente: Encuesta Nacional de Hogares sobre condiciones de vida y pobreza INEI y Ministerio del Trabajo y Promoción del Empleo

Elaboración: Fernando Cuadros

El escaso número de empresas (solo el 7,6\% de las microempresas desde la vigencia de la ley 28015) y trabajadores (solo el 7,3\% de los trabajadores de la microempresa) que han ingresado a la formalidad revelan que el incentivo creado no era el más adecuado y nos confrontan con la necesidad de buscar el mismo objetivo a través de políticas complementarias, basadas en un mayor sacrificio estatal, como son las políticas de mejora de la competitividad basadas en el incremento de la productividad.

En esa línea, la OIT, a través del documento denominado «Trabajo decente en las Américas: una agenda hemisférica 2006-2015», sugiere, con el propósito de mejorar la calidad del empleo en las micro y pequeñas empresas, el desarrollo de políticas que mejoren los niveles de protección social y el desarrollo de capacidades de representación gremial, políticas que mejoren el acceso de las MYPES a los mercados y servicios (con especial énfasis en la mejora de la productividad) y mejorar el marco reglamentario (barreras de acceso al mercado) ${ }^{18}$.

18 «183. Se propone actuar en tres ámbitos prioritarios. En primer lugar, es necesario iniciar y dar prioridad a acciones que se centren en los problemas de la baja protección social y de su inadecuada representación, lo cual requiere cambios orientados a la legalización de las MYPE, nuevos esquemas de protección social para sus trabajadores y el desarrollo de las capacidades de negociación y articulación de los gremios de trabajadores y empresarios, ya que, aunque se reconoce que en 
Sobre este tema, es importante destacar el siguiente comentario:

Como se desprende claramente de la revisión de la Ley MYPE, esta se centra en la disminución de los beneficios laborales que les corresponderían de acuerdo al régimen laboral general ${ }^{19}$ a los nuevos trabajadores contratados por empresas con no más de 100 trabajadores y ventas anuales hasta el monto máximo de 1.700 unidades impositivas tributarias (a partir de la entrada en vigencia de la ley), con el propósito de «promover la competitividad, formalización y desarrollo de la micro y pequeña empresa». Ello, desde el punto de vista económico, implica la reducción de los denominados costos laborales no salariales, es decir, aquellos adicionales a la remuneración mensual percibida por los trabajadores ${ }^{20}$.

Sin embargo, cabe preguntarse si realmente una reducción de costos laborales no salariales constituye el instrumento más conveniente para promover la competitividad y la formalización de las micro y pequeñas empresas. Consideramos que no, por las razones que se exponen a continuación.

En lo que respecta a temas de competitividad y más precisamente en lo referido a la competitividad en materia laboral, la variable más relevante es el costo laboral por bien producido ${ }^{21}$ (o costo laboral unitario) y no los costos laborales no salariales.

varios países se vienen aplicando políticas de fomento de la competitividad que incluyen a las MYPE, las políticas que se refieren a sus derechos y a la protección social de sus trabajadores no han avanzado al mismo ritmo. 184. En segundo lugar, se precisan políticas que mejoren el acceso de las MYPE a los mercados y servicios. En este caso, si contaran con un entorno de servicios productivos apropiados en materia de finanzas, capacitación, mercadotecnia, calidad, información, etcétera, las MYPE podrían incrementar su presencia y participación en el mercado, aumentar la productividad y crear y mantener empleos de calidad. En este marco, es especialmente importante diseñar y aplicar políticas que alienten a las microempresas y pequeñas empresas a incorporarse a conglomerados productivos. Para ello, podría ser especialmente eficaz ofrecer algún tipo de incentivo a las empresas que constituyen el núcleo del conglomerado para que promuevan la incorporación de las microempresas y pequeñas empresas. 185. En tercer lugar, estas medidas no tendrán el impacto que debieran si los marcos reglamentario y de políticas no son propicios al desarrollo de las MYPE. Por un lado, tal como ha puesto de manifiesto un estudio de la OIT, existe una suerte de paradoja en lo que se refiere a la promoción de las MYPE, ya que, mientras se implantan y ejecutan programas de apoyo específicos para ellas, el marco reglamentario es en general adverso para las empresas pequeñas en una serie de esferas que van desde los sistemas de registro para la apertura de empresas hasta los reglamentos de comercio, finanzas y exportación que limitan seriamente la capacidad de este tipo de empresas. A ello hay que añadir los problemas que tienen las empresas de cualquier tamaño de la región en lo que el Banco Mundial ha denominado «entorno de negocios»» (OIT. «Trabajo decente en las Américas: una agenda hemisférica, 2006-2015. Informe del Director General». Brasilia: OIT, 2006, p. 57. Este informe puede ser consultado en el sitio web de la OIT (http://www.ilo.org/public/spanish/standards/relm/rgmeet/americas.htm)).

$19 \mathrm{El}$ régimen laboral general que rige en nuestro país es el previsto en el Texto Único Ordenado de la Ley de Productividad y Competitividad Laboral, aprobado por decreto supremo 003-97-TR, y en las demás normas que —con carácter general- regulan los beneficios laborales.

20 CUADROS LUQUE, Fernando. «Nueva Ley MYPE: ¿es el remedio peor que la enfermedad?». Trabajo \& Desarrollo, 7 (2010), p. 26.

21 Se refiere al gasto promedio en mano de obra que debe realizar una empresa para producir una unidad de los bienes que oferta. 
El costo laboral unitario depende de dos variables, el costo laboral por trabajador (que incluye los costos salariales y no salariales) y el producto por trabajador (productividad del trabajo).

De esta manera:

UNA VISIÓN

- CLU = costo laboral unitario (o costo laboral medio por bien producido)

- CLT $=$ costo laboral total (incluye costos salariales y no salariales)

- $\mathrm{E}=$ número de trabajadores

- $\mathrm{Q}=$ valor de la producción total

- CLT/E = costo laboral medio por trabajador (o costo laboral por unidad de trabajo)

- Q/E = producto medio por trabajador (variable proxy de la productividad del trabajo)

$$
\mathrm{CLU}=\frac{\mathrm{CLT} / \mathrm{E}}{\mathrm{Q} / \mathrm{E}}
$$

Existen pues dos formas de reducir el costo laboral unitario: a través de una reducción de los costos laborales totales y a través de una mejora (incremento) de la productividad.

Para Cuadros Luque,

La primera de ellas es la menos conveniente por los efectos perjudiciales que generaría en la sociedad al cargarle todo el costo del crecimiento a los trabajadores ${ }^{23}$ (lo cual sería un catalizador de conflictos sociales) y porque posee un margen reducido de acción (no se puede aplicar todos los años). También se debe tener en consideración que una política enfocada únicamente en la disminución de costos laborales por trabajador reduciría el poder adquisitivo de la masa asalariada, lo cual implicaría una disminución del consumo y la demanda interna y por ende, una desaceleración de la inversión y el crecimiento de los sectores enfocados en el mercado interno. En última instancia, de acuerdo a la evidencia empírica internacional, la reducción de costos laborales (salariales o no salariales) por trabajador tampoco tendría un efecto significativo en la generación de empleo forma ${ }^{24}$. 
En el mismo sentido opinan Gamero y Balbín al señalar:

En el caso del régimen agrario y del régimen MYPE, como ya se ha adelantado, se pretende combatir el empleo no registrado asumiendo que su regularización se producirá una vez que se haya rebajado el estándar de protección laboral (que bajo esta perspectiva resultaría excesivamente costoso), sin considerar que el empleo informal tiene también causas estructurales y no necesariamente depende del análisis costo-beneficio que realiza el empleador. Además, no existe evidencia empírica que permita sostener que una política con componentes legislativos basada en la rebaja del estándar de protección laboral haya logrado algún resultado positivo en el objetivo de la formalización del empleo ${ }^{25}$.

Como se puede apreciar, no existe evidencia que demuestre que el modelo de reducción de costos laborales es una política efectiva en el fomento de la formalización y, de otro lado, la política de formalización laboral basada en la reducción de los denominados costos laborales es una política socialmente inconveniente.

\section{EL RÉGIMEN DE LA LEY MYPE Y LA AFECTACIÓN A DERECHOS FUNDAMENTALES LABORALES Y DE PROTECCIÓN SOCIAL}

\begin{tabular}{|c|c|c|c|}
\hline \multirow{2}{*}{ REFERENCIA } & \multirow{2}{*}{ RÉGIMEN GENERAL } & \multicolumn{2}{|c|}{ RÉGIMEN LABORAL ESPECIAL DE LA MYPE } \\
\hline & & MICROEMPRESA & PEQUEÑA EMPRESA \\
\hline Remuneración & $S / .550,00$ & $\begin{array}{l}\text { S/. 550,00 la Confederación } \\
\text { Nacional de Trabajadores } \\
\text { (CNT) puede aprobar una re- } \\
\text { muneración menor }\end{array}$ & $S / .550,00$ \\
\hline Asignación familiar & $\begin{array}{l}10 \% \text { de la Remuneración } \\
\text { mínima vital (RMV) por hijo }\end{array}$ & No & No \\
\hline CTS & $\begin{array}{l}\text { Equivalente a una remune- } \\
\text { ración mensual por cada } \\
\text { año. No tiene tope. Fraccio- } \\
\text { nes se pagan en dozavos y } \\
\text { treintavos. }\end{array}$ & No & $\begin{array}{l}\text { Equivalente a } 5 \text { remu- } \\
\text { neraciones diarias por } \\
\text { cada año. Tope de } 90 \\
\text { remuneraciones diarias. } \\
\text { Fracciones en dozavos y } \\
\text { treintavos. }\end{array}$ \\
\hline Gratificaciones & $\begin{array}{l}1 \text { remuneración mensual } \\
\text { (RM) en julio y diciembre }\end{array}$ & No & $\begin{array}{l}\text { 1/2 remuneración en julio } \\
\text { y en diciembre }\end{array}$ \\
\hline $\begin{array}{l}\text { Despido arbitrario } \\
\text { o injustificado }\end{array}$ & $\begin{array}{l}1 \frac{1}{2} \text { remuneración mensual } \\
\text { por año. Tope de } 12 \text { remu- } \\
\text { neraciones }\end{array}$ & $\begin{array}{l}10 \text { remuneraciones diarias } \\
\text { por año, con un máximo de } \\
90 \text { remuneraciones diarias. } \\
\text { Fracciones en dozavos. }\end{array}$ & $\begin{array}{l}20 \text { remuneraciones } \\
\text { diarias por año, con un } \\
\text { máximo de } 120 \text { remu- } \\
\text { neraciones diarias. Frac- } \\
\text { ciones en dozavos. }\end{array}$ \\
\hline
\end{tabular}




\begin{tabular}{|c|c|c|c|}
\hline $\begin{array}{l}\text { Sobretasas } \\
\text { nocturnas }\end{array}$ & $\mathrm{RMV}+35 \%$ & No se aplica si es habitual & $\begin{array}{l}\text { No se aplica si es } \\
\text { habitual }\end{array}$ \\
\hline Vacaciones & 30 días & 15 días & 15 días \\
\hline Seguro de vida & $\begin{array}{l}\text { Para trabajadores con } 4 \\
\text { años de servicios }\end{array}$ & No & Sí \\
\hline Seguro en salud & $\begin{array}{l}\text { EsSalud afiliación obligato- } \\
\text { ria. Aporte de } 9 \% \text { a cargo } \\
\text { del empleador. }\end{array}$ & $\begin{array}{l}\text { Seguro Integral de Salud (SIS) } \\
\text { conductor y trabajador son } \\
\text { afiliados al componente semi- } \\
\text { subsidiado. Empleador aporta } \\
\text { la mitad y el Estado un monto } \\
\text { igual. EsSalud: acceden como } \\
\text { asegurados regulares sin sub- } \\
\text { sidio estatal. }\end{array}$ & $\begin{array}{l}\text { Conductor y trabajador } \\
\text { son afiliados regulares } \\
\text { a EsSalud. }\end{array}$ \\
\hline $\begin{array}{l}\text { Seguro comple- } \\
\text { mentario de traba- } \\
\text { jo de riesgo (SCTR) }\end{array}$ & $\begin{array}{l}\text { Porcentaje adicional varia- } \\
\text { ble según actividad }\end{array}$ & SIS no previsto. EsSalud sí. & Sí aplica el SCTR. \\
\hline Pensiones & $\begin{array}{l}\text { Afiliación obligatoria al Sis- } \\
\text { tema Privado de Pensiones } \\
\text { (SPP) o al Sistema Nacional } \\
\text { de Pensiones (SNP). Aporte } \\
\text { a cargo del trabajador. }\end{array}$ & $\begin{array}{l}\text { Afiliación al sistema de pen- } \\
\text { siones sociales. Aporte del } \\
\text { trabajador hasta un máximo } \\
\text { del } 4 \% \text { de la RMV. Aporte Es- } \\
\text { tado igual. Sistema de Cuanta } \\
\text { individual del afiliado. }\end{array}$ & $\begin{array}{l}\text { Conductor y trabajador } \\
\text { se afilian al SPP y SNP. La } \\
\text { afiliación del trabajador } \\
\text { es obligatoria. }\end{array}$ \\
\hline
\end{tabular}

En primer lugar debemos señalar que el régimen laboral especial de la Ley MYPE sí tiene directa incidencia en un conjunto de derechos laborales y de protección social fundamentales.

¿Es razonable la reducción del descanso físico vacacional bajo la visión de considerarlo un «costo laboral»? Sobre el particular, en el estudio realizado por la OIT denominado «Working Time Around the World: Trends in working hours, laws and policies in a global comparative perspective» se señala que:

En lo que se refiere a los países donde se registra la mayor incidencia de jornadas laborales extensas en 2004-2005 (con más de 48 horas a la semana), Perú encabezó la lista con 50,9 por ciento de los trabajadores [...], seguido por la República de Corea con 49,5 por ciento, Tailandia con 46,7 por ciento [...] y Pakistán con 44,4 por ciento. En los países desarrollados, donde las jornadas laborales suelen durar menos, esta proporción fue de 25,7 por ciento en Reino Unido, 25,5 por ciento en Israel, 20,4 por ciento en Australia, 19,2 por ciento en Suiza y 18,1 por ciento en Estados Unidos.

En el mismo sentido, según la base de datos del Instituto Nacional de Estadística e Informática (INEI, «Encuesta Nacional de Hogares sobre condiciones de vida y pobreza, continua 2004-2009») los asalariados privados con jornadas superiores a 48 horas semanales 
alcanzaban el 45,9\% en el año 2009, en términos absolutos un total de 2,2 millones declararon laborar jornadas superiores a la máxima.

Por tales motivos, no se encontraría justificada la reducción del descanso físico vacacional en nuestro país. Aun más, el régimen especial suprime el derecho de los trabajadores de la microempresa a contar con la CTS.

Sobre el particular debemos destacar que uno de los mecanismos de control de la OIT con relación al cumplimiento de las normas internacionales (convenios ratificados) lo constituye la presentación de memorias anuales, conforme a lo dispuesto en el artículo 22 de la Constitución de la $\mathrm{OIT}^{26}$.

La revisión de las memorias anuales sobre las medidas adoptadas por los países para dar cumplimiento a los convenios que han ratificado corre a cargo de la Comisión de Expertos en Aplicación de Convenios y Recomendaciones, esta es la encargada de determinar en qué medida la legislación y la práctica de cada país es conforme a las obligaciones contenidas en los convenios ratificados. La Comisión puede, sobre la base del análisis de las memorias, elaborar observaciones (en cuanto al respeto y cumplimiento de las obligaciones asumidas por los Estados) o solicitudes directas, solo las primeras se publican en el informe anual que elabora la Comisión.

El informe de la Comisión correspondiente a la 96 reunión de la Conferencia Internacional del Trabajo, incluye un conjunto de observaciones en relación con el nivel de cumplimiento de las obligaciones asumidas por nuestro país a partir de la ratificación de ciertos convenios. Una de las observaciones está referida al nivel de cumplimiento que presenta nuestro país con relación al Convenio 44 sobre el desempleo.

En dicho informe, repitiendo una observación anterior, la Comisión considera que tanto la CTS como la indemnización por despido arbitrario, no constituyen un sistema de protección contra el desempleo en los términos definidos por el Convenio $44^{27}$. El Convenio define el

26 OIT, Constitución, artículo 22: «Artículo 22.- Cada uno de los Miembros se obliga a presentar a la Oficina Internacional del Trabajo una memoria anual sobre las medidas que haya adoptado para poner en ejecución los convenios a los cuales se haya adherido. Estas memorias serán redactadas en la forma que indique el Consejo de Administración y deberán contener los datos que este solicite».

27 Convenio 44 sobre desempleo, artículo1: «Artículo 1.1. Todo Miembro de la Organización Internacional del Trabajo que ratifique el presente Convenio se obliga a mantener un sistema que garantice a los desempleados involuntarios comprendidos en este Convenio: a) una indemnización, es decir, el pago de una cantidad devengada con motivo de las cotizaciones abonadas en virtud del empleo del beneficiario afiliado a un sistema obligatorio o voluntario; o b) un subsidio, es decir, una prestación que no constituye ni una indemnización, ni un socorro concedido en virtud de medidas generales de asistencia a los indigentes, pero que puede constituir la remuneración de un empleo en trabajos de asistencia organizados de acuerdo con las condiciones previstas por el artículo 9; o bien c) una combinación de indemnizaciones y subsidios. 2. A condición de que garantice a todas las personas a las que se aplica el presente Convenio las indemnizaciones o subsidios previstos en el párrafo 1, este sistema podrá ser: a) un sistema de seguro obligatorio; b) un sistema de seguro 
conjunto de prestaciones posibles (indemnizaciones, subsidios o una combinación de ambas) y los instrumentos para otorgarlas (seguro obligatorio, voluntario, una combinación de ambos o un sistema de seguros complementado con uno asistencial).

La Comisión concluye señalando que queda a la espera de recibir la información referida a los estudios actuariales y los proyectos normativos que permitan poner en marcha un seguro de desempleo, a cuya entrega se había comprometido nuestro país.

El seguro de desempleo tiene como propósito cubrir una contingencia, la del desempleo o la de la pérdida de un puesto de trabajo, al suprimir la CTS el trabajador de la micro empresa queda en total desprotección y sin cobertura para esta contingencia, de esa forma, se vulnera el derecho de los trabajadores de la microempresa a no ser tratados diferentes si no existen elementos objetivos y razonables para hacerlo, consecuentemente, esta medida es discriminatoria.

En cuanto a la cobertura en salud para los trabajadores de la microempresa, podemos señalar que el artículo 48 de la Ley MYPE incluyó a los trabajadores de la microempresa en el denominado régimen Semisubsidiado del SIS. Con esta disposición, la protección de los trabajadores dependientes en el ámbito de las microempresas quedaba sujeta, en materia de seguridad social en salud, a la protección que dicha norma y su posterior reglamento establecieron, sustrayendo a los trabajadores de la microempresa del ámbito de la seguridad social en salud que rige para el resto de los trabajadores dependientes y que está regulado por la ley 26790, Ley de Modernización de la Seguridad Social en Salud y su reglamento aprobado por decreto supremo 009-97-SA.

Por ello, al no existir una disposición específica en el citado decreto legislativo que los incluya en la cobertura del Seguro Complementario de Trabajo de Riesgo (SCTR), los trabajadores de la microempresa en materia seguridad social en salud quedaron excluidos de la afiliación al SCTR y sometidos únicamente a la cobertura que el decreto legislativo y su posterior reglamento definieron.

De manera contraria a lo establecido para los trabajadores de la microempresa, el artículo 40 del reglamento establece que los trabajadores de la pequeña empresa tienen derecho a un SCTR a cargo de su empleador cuando corresponda por la actividad que realicen, conforme a la ley 26790, Ley de Modernización de la Seguridad Social en Salud.

voluntario; c) una combinación de los sistemas de seguro obligatorio y de seguro voluntario; d) cualquiera de los sistemas precitados completado con un sistema de asistencia. 3 . Las condiciones en que los trabajadores desempleados podrán pasar del régimen de indemnizaciones al régimen de subsidios, si el caso se presentare, serán fijadas por la legislación nacional».

UNA VISIÓN

PONDERADA DE

LA LEGISLACIÓN

LABORAL:

COMENTARIOS AL

RÉGIMEN MYPEY

A LA PROPUESTA

DE «LEY DE LA

NUEVA EMPRESA»

A WEIGHTED VIEW

OF LABOR LAW:

COMMENTARIES

ON THE MSE

REGIME AND

THE PROPOSAL

"LAW OF NEW

ENTERPRISE" 
Nuevamente la norma establece una diferencia de trato no sustentada en motivos objetivos, privando a los trabajadores de la microempresa de la afiliación al SCTR, aun cuando realicen algunas de las actividades de alto riesgo que determinan la afiliación a este régimen. Lo que sucederá en este caso es que los trabajadores que padezcan algún deterioro en su salud por incumplimiento de medidas de seguridad y salud en el trabajo accederán a las prestaciones del régimen general sin que se obtenga información importante sobre los riesgos en el trabajo y generando un subsidio que atenta contra la solidaridad del sistema de seguridad social.

Sobre el particular, la OIT a través del «Estudio financiero-actuarial y de la gestión de EsSalud: análisis y recomendaciones técnicas», elaborado en el mes de mayo de 2005, ha señalado:

Remitiéndonos al Convenio 102 de la OIT, el cual establece normas expresas relativas a la responsabilidad de financiamiento, resulta necesaria la extensión de la cobertura de los riesgos del trabajo a todos los trabajadores sin importar el nivel de riesgos a que estén asociados; en la situación actual, el fondo del Seguro de Salud (Regular y Agrario) está subsidiando gran parte de las prestaciones propias de riesgos laborales (que incluye prestaciones sociales, económicas y de salud), no solo en virtud de las carencias del marco jurídico (cumplimiento del Convenio 102 en materia de cobertura de riesgos laborales), sino también como consecuencia de los problemas de registro y clasificación de las atenciones derivadas de riesgos del trabajo ${ }^{28}$.

Es por esta situación que el mismo estudio ha señalado:

Estas consideraciones invitan a la necesidad de acciones en dos líneas: i) desde el punto de vista de la gestión, la necesidad de que EsSalud separe y registre completamente el financiamiento y los gastos relativos a riesgos laborales (tanto de accidentes como de enfermedades profesionales) de todos los trabajadores afiliados y no solo los de trabajadores adscritos al SCTR, y ii) la incorporación de cambios jurídicos ante una posible agenda de reformas futuras tendientes a darle compleción al marco jurídico de la seguridad social en función de la Norma Mínima de Seguridad Social (Convenio 102) ${ }^{29}$.

Esta exclusión genera un trato diferenciado incompatible con nuestra constitución; viola el principio de universalidad ${ }^{30}$ de la seguridad social,

28 OIT. «Estudio financiero-actuarial y de la gestión de EsSalud: análisis y recomendaciones técnicas». Lima: Oficina Subregional de la OIT para los Países Andinos, 2005, p. 62.

29 L. cit.

30 Se define este principio de la siguiente manera: «UNIVERSALIDAD: en sus dos vertientes (la objetiva y la subjetiva). La objetiva significa que la seguridad social debe cubrir todas las contingencias (riesgos) a las que está expuesto el hombre que vive en sociedad. La subjetiva, que todas las personas deben estar amparadas por la seguridad social. Este principio deriva de su naturaleza de Derecho Humano Fundamental» (MURRO OBERLIN, Ernesto Ramón. «El dilema de la seguridad social en el cono sur». Oficina Internacional del Trabajo: 2004, p. 24). Sobre este principio, cabe 
afecta el principio de integralidad al privar a los trabajadores de la microempresa de las prestaciones y cobertura del seguro complementario de trabajo de riesgo y también desconoce lo dispuesto en el artículo $31^{31}$ del Convenio 102 de la OIT.

En cuanto a la protección social en pensiones debemos señalar que el artículo 49 de la Ley MYPE establece que los trabajadores y conductores de la microempresa comprendidos en dicha norma podrán afiliarse a cualquiera de los regímenes previsionales contemplados en el decreto ley 19990, ley que crea el Sistema Nacional de Pensiones de la Seguridad Social, y en el decreto supremo 054-97-EF, Texto Único Ordenado de la Ley del Sistema Privado de Administración de Fondos de Pensiones.

Los trabajadores y conductores de la microempresa comprendidos en la Ley MYPE que no se encuentren afiliados o sean beneficiarios de algún régimen previsional podrán optar por el Sistema de Pensiones Sociales contemplado en el título III sobre el Aseguramiento en Salud y Sistema de Pensiones Sociales de la Ley de Promoción de la Competitividad, Formalización y Desarrollo de la Micro y Pequeña Empresa. Ello se aplica, asimismo, para los conductores de la microempresa.

Un primer comentario está dirigido a resaltar un evidente problema de constitucionalidad: para los trabajadores de la microempresa la afiliación a un régimen de pensiones es opcional, es decir, no es obligatoria.

De manera contraria a la afiliación obligatoria que otorga cobertura universal a los trabajadores dependientes del régimen general de la seguridad social en pensiones, tanto a través del régimen público como del privado, para este segmento de trabajadores la afiliación es opcional. Es previsible que a partir de un análisis costo beneficio que pierda de vista la importancia de una cobertura previsional futura para las contingencias que acontezcan una vez perdido el empleo, los trabajadores de la microempresa podrían decidir no afiliarse a ningún sistema previsional para mantener su poder adquisitivo y percibir el íntegro de su salario sin sufrir un descuento con fines contributivos previsionales.

Este trato diferenciado vulnera el principio-derecho de igualdad al no encontrar suficientes motivos objetivos que lo sustenten. De esta

recordar que mediante sentencia recaída en el expediente 1417-2005-AA/TC (caso Manuel Anicama Hernández) el TC ha realizado una definición de la seguridad social como la garantía institucional que expresa por excelencia la función social del Estado. Se concreta en un complejo normativo estructurado al amparo de la doctrina de la contingencia y la calidad de vida. Por ello, requiere de la presencia de un supuesto fáctico al que acompaña una presunción de estado de necesidad (cese en el empleo, viudez, orfandad, invalidez, entre otras) que condiciona el otorgamiento de una prestación pecuniaria y/o asistencial, «regida por los principios de progresividad, universalidad y solidaridad, y fundada en la exigencia no solo del mantenimiento, sino en la elevación de la calidad de vida».

31 Convenio 102 de la OIT: «Artículo 31.- Todo Miembro para el que esté en vigor esta parte del convenio deberá garantizar a las personas protegidas la concesión de prestaciones en caso de accidente del trabajo y de enfermedad profesional; de conformidad con los artículos siguientes de esta parte».

UNA VISIÓN

PONDERADA DE

LA LEGISLACIÓN

LABORAL:

COMENTARIOS AL

RÉGIMEN MYPEY

A LA PROPUESTA

$D E \ll L E Y$ DE LA

NUEVA EMPRESA»

A WEIGHTED VIEW

OF LABOR LAW:

COMMENTARIES

ON THE MSE

REGIME AND

THE PROPOSAL

"LAW OF NEW

ENTERPRISE" 
forma se crean dos segmentos de trabajadores: uno cubierto por el régimen general, cubierto de manera obligatoria por la seguridad social en pensiones, y otro del régimen de la ley con cobertura opcional y, por tanto, contingente. Esta disposición también afecta el principio de universalidad de la seguridad social ya mencionado y definido anteriormente en este trabajo.

En cuanto al carácter temporal o permanente del régimen, el artículo 42 de la Ley MYPE señala que el Régimen Laboral Especial es de naturaleza permanente, de esta forma, la empresa cuyo nivel de ventas o el número de trabajadores promedio de dos años consecutivos supere el nivel de ventas o el número de trabajadores límites establecidos en la presente ley para clasificar a una empresa como Micro o Pequeña Empresa, podrá conservar por un año calendario el Régimen Laboral Especial correspondiente. Luego de este período, la empresa pasará definitivamente al Régimen Laboral que le corresponda.

Como se puede apreciar, la permanencia en este régimen depende del empleador en tanto este podrá controlar los niveles de venta anuales así como el número de trabajadores que determinan el acceso y permanencia en el régimen especial. Así, el régimen laboral especial para la microempresa no ha sido configurado como un régimen de carácter temporal, de esta forma, se introduce un trato diferenciado de carácter permanente, lo que afecta de inconstitucionalidad a este régimen ${ }^{32}$.

Finalmente, apreciamos que no existe ningún incentivo para promover la libertad sindical en este segmento empresarial. Resulta crucial la reducción del límite mínimo de trabajadores impuesto para constituir un sindicato de empresa o, en todo caso, el desarrollo de una legislación que favorezca niveles de negociación supraempresariales y la afiliación directa a organizaciones sindicales de grado superior como federaciones o confederaciones; ello en tanto el $60 \%$ de asalariados privados se encuentra ocupado en empresas con menos de veinte trabajadores.

El análisis efectuado en este punto pone de relieve la intervención grave de una regulación especial, diferenciada del régimen general, en un conjunto de derechos de contenido constitucional.

Con ello, la política de fomento de la formalización del empleo en el segmento de la microempresa ${ }^{33}$, aparentemente neutra, genera

32 Los fundamentos jurídicos 47 y 82 de la sentencia del TC recaída en el expediente 00027-2006-Al refuerzan el carácter temporal de los regímenes promocionales.

33 Nótese que las políticas de fomento del empleo se distinguen de las políticas de trato diferenciado, denominadas en nuestra legislación laboral «regímenes especiales», como es el régimen de construcción civil, para citar solo un ejemplo de adaptación del régimen general laboral a las particulares características de una actividad económica caracterizada por su carácter permanente pero discontinuo. En estas últimas, el propósito es el de adaptar la regulación de las relaciones individuales o colectivas de trabajo a las particulares características de una actividad económica, en los términos expuestos en la primera parte de este artículo. Estas políticas expresan el respeto de las 
efectos negativos que inciden directamente en el ejercicio de derechos constitucionales, y por ello fundamentales, de contenido social, afectando a importantes grupos de trabajadores y ampliando las brechas de desigualdad que existen en nuestro sistema de relaciones de trabajo.

\section{ANÁLISIS DEL RÉGIMEN LABORAL DE LA "NUEVA EMPRESA»}

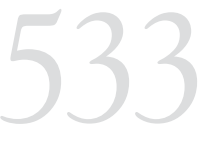

UNA VISIÓN

PONDERADA DE

LA LEGISLACIÓN

LABORAL:

COMENTARIOS AL

RÉGIMEN MYPE Y

A LA PROPUESTA

$D E$ «LEY DE LA

NUEVA EMPRESA»

A WEIGHTED VIEW

OF LABOR LAW:

COMMENTARIES

ON THE MSE

REGIME AND

THE PROPOSAL

"LAW OF NEW

ENTERPRISE" participacionistas, gerentes generales, directores de personas jurídicas catalogadas como contribuyentes de categoría mediana o grande;

iv) la nueva empresa no sea accionista o socia de un persona jurídica con fines de lucro; del mismo modo estas o aun las no lucrativas no pueden constituirla o convertirse en socias suyas;

v) no asocie o sea accionista suya una persona que es socia o accionista de otra nueva empresa;

vi) no exista vinculación económica entre nuevas empresas; esto para fines tributarios, laborales y financieros, conforme a lo regulado en los artículos 6 y 7 del proyecto de Ley de la Nueva Empresa.

\section{Comentario:}

Se estipula que el régimen laboral no tiene carácter permanente pues su vigencia está sujeta al cumplimiento de los requisitos establecidos en el artículo 2. En ese sentido, el régimen en la práctica puede ser de carácter permanente siempre que la empresa cumpla con los requisitos para ser considerada una nueva empresa.

Conforme a lo dicho anteriormente, un régimen promocional no debería tener como característica el ser permanente, su otorgamiento 
a un conjunto de empresas debe estar vinculado a un monitoreo y evaluación del desarrollo de la unidad empresarial en un límite de tiempo determinado y sujeto a la verificación del cumplimiento de metas (benchmarking). De lo contrario esta política de promoción deviene en discriminatoria y, consecuentemente, inconstitucional.

\section{IV.2. Beneficios sociales en la nueva empresa}

\section{a. De la remuneración mínima de la nueva empresa:}

Se crea una Remuneración Mínima para la Nueva Empresa (RMNE) diferente a la Remuneración Mínima Vital (RMV).

- La RMNE se fija en función de la retribución horaria (RH), la cual se compone de la siguiente manera:

- el pago en efectivo otorgado a los trabajadores por hora laborada;

- el porcentaje de ley que corresponde por seguridad social;

- el porcentaje de ley que corresponde por CTS;

- el porcentaje de ley que corresponde por vacaciones y gratificaciones.

- La RMNE se calcula sobre la base de los componentes de la RH dividida entre cuatro semanas, dividiendo dicho resultado entre cuarenta y ocho horas.

\section{b. Del horario de trabajo:}

El artículo 39 del proyecto de ley indica que «el horario de trabajo en el régimen de la N.E. es de ocho (08) horas diarias». Asimismo, indica que el tiempo adicional constituya horas extras y se calcula sobre la base de la RH.

\section{c. De las vacaciones:}

Si el trabajador de la Nueva Empresa hubiere cumplido con el récord vacacional, conforme lo regula el artículo 10 del decreto legislativo 710, entonces tendrá derecho a quince días de vacaciones como mínimo.

\section{d. Del despido injustificado:}

Se señala que ante el despido injustificado cabe una indemnización equivalente a ciento veinte $\mathrm{RH}$ por año laborado con un máximo de mil cuarenta RH.

\section{e. De la seguridad social:}

Se señala que tanto socios como trabajadores de la nueva empresa son asegurados regulares, conforme al artículo 1 de la ley 26790; por otro lado, es facultativa su incorporación a cualquiera de los regímenes previsionales. 
f. Demás beneficios sociales:

Los trabajadores de la nueva empresa tendrán derecho a percibir, además, los beneficios sociales que se encuentren regulados para el régimen común de la actividad privada — en lo que resultase aplicable_-, aun cuando no hubieren sido regulados en el proyecto de Ley de la Nueva Empresa.

\section{COMENTARIO}

En pocas palabras, la «remuneración mínima» que se pretende crear incluiría los complementos no salariales (CTS, vacaciones, gratificaciones y el aporte al seguro social) que el trabajador dejaría de percibir al trasladarse a este nuevo régimen. Con ello, el trabajador pierde un mecanismo de protección contra el desempleo como es la CTS, con las graves consecuencias que ello traería conforme a lo dicho en los numerales anteriores de este informe.

De otro lado, creemos que sí es necesario regular una remuneración mínima por tratarse de un derecho fundamental que no puede ser suprimido ni desconocido para un trabajador aun cuando preste servicios en una micro empresa. La propuesta no tiene como punto de partida una remuneración mínima sino que tiene como base de cálculo a la remuneración que el trabajador percibe por hora trabajada, que puede ser menor a la remuneración mínima.

Sugerimos que el punto de partida o la base del cálculo debe tener en consideración a la RMV, admitiendo la posibilidad de incluir otros complementos no salariales pero excluyendo la contribución a EsSalud, pues como se puede notar «remuneración mínima» incluye el aporte a la Seguridad Social. En ese sentido, no creemos que la norma se refiere al aporte al Seguro Social de Salud pues este aporte corre a cargo del empleador, entendemos más bien que se trataría del aporte para el régimen pensionario - público o privado— que, al parecer, correría por cuenta del trabajador y que no aparece como obligatorio; de cualquier forma es necesaria una precisión al respecto.

Finalmente, sobre este punto debemos dejar sentado que —en nuestra opinión- enriquecería la propuesta una regulación de la RMV que permita establecer, sobre la base de criterios objetivos (inflación, o canasta básica de consumo), diferentes remuneraciones mínimas de acuerdo a las distintas realidades socioeconómicas de nuestro país.

Por otro lado, en lo que respecta al sistema de seguridad social planteado, cabe señalar que el «costo no salarial» (contribuciones de salud y pensiones) es de $22 \%$ aproximadamente, costo que encarece la mano de obra, especialmente la de los menos calificados; por ello, sería especialmente promocional reducir el aporte en salud y pensiones,

UNA VISIÓN

PONDERADA DE

LA LEGISLACIÓN

LABORAL:

COMENTARIOS AL

RÉGIMEN MYPEY

A LA PROPUESTA

$D E$ «LEY DE LA

NUEVA EMPRESA»

A WEIGHTED VIEW

OF LABOR LAW:

COMMENTARIES

ON THE MSE

REGIME AND

THE PROPOSAL

"LAW OF NEW

ENTERPRISE" 
compensando la diferencia con aportaciones fiscales a los fondos de salud y pensiones (sistema nacional de pensiones) respectivamente.

No cabe un trato diferenciado en materia de seguridad social basado en una menor cobertura para los trabajadores de una microempresa (en la práctica, la denominada «nueva empresa» es una microempresa), estos deberían estar afiliados al régimen contributivo de la seguridad social en salud como afiliados regulares aunque en este caso el Estado podría asumir un subsidio parcial de la contribución. De igual forma, la afiliación a un sistema de pensiones debe ser obligatoria y el Estado debería asumir un subsidio parcial de la contribución a cargo del trabajador para incentivar la formalización del empleo.

\section{CONCLUSIONES}

Las diferencias en el trabajo, esto es, las particularidades de la prestación de servicios son el primer sustento de un trato diferenciado en materia laboral que autoriza a un trato diferenciado legítimo.

Los tratos diferenciados que tienen como sustento el rol estatal de promoción del empleo o de un determinado sector productivo que por sus características particulares (por sus diferencias objetivas en contraposición a otros sectores productivos) merece una política de promoción son legítimos y constitucionales.

En el caso del régimen MYPE, la reducción del descanso físico vacacional no se justifica, puesto que, conforme los estudios realizados por la OIT y por el INEI, los índices de trabajadores que laboran durante jornadas mayores a 48 horas semanales son elevados.

En materia de seguridad social, el régimen MYPE vulnera el derechoprincipio a la igualdad, así como el principio de universalidad que caracteriza el derecho a la seguridad social. Ello debido a que restringe el acceso al SCTR y establece que la afiliación a un sistema de seguridad social en pensiones es opcional.

Cabe señalar que conforme al régimen en mención, los trabajadores de la microempresa cuentan con un régimen semisubsidiado en salud - a cargo del SIS-, no obstante, a diferencia de los trabajadores de la pequeña empresa, no cuentan con el SCTR. En este sentido, se establece una medida discriminatoria contra los trabajadores de microempresas, toda vez que prescinde de su derecho a contar con un SCTR; vulnerando, del mismo modo, el principio de universalidad de la seguridad social.

Del mismo modo, respecto a pensiones, el régimen MYPE resulta inconstitucional en tanto establece que la afiliación a este sistema es opcional, vulnerando el principio de universalidad del mismo. 
El régimen MYPE tiene carácter permanente, pues la pertenencia al régimen laboral especial dependerá del control por parte del empleador de las características que determinan si una empresa es micro o pequeña. Razón por la cual, este régimen, al no tener carácter temporal, constituye una medida discriminatoria y, por ende, inconstitucional.

El régimen MYPE no promueve la libertad sindical, toda vez que la legislación vigente señala que un sindicato no puede constituirse con menos de veinte trabajadores aunque el $60 \%$ de asalariados privados cuenta con empresas cuya totalidad de trabajadores no alcanza dicho número.

Por su parte, la «Ley de la Nueva Empresa» introduciría al ordenamiento jurídico un régimen laboral con carácter permanente, pues bastará para que este tenga vigencia el cumplimiento de los requisitos establecidos en su artículo 2.

Así, su otorgamiento debería estar vinculado a un monitoreo y evaluación del desarrollo de la unidad empresarial en un límite de tiempo determinado y sujeto a la verificación del cumplimiento de metas. De lo contrario, esta política de promoción deviene en discriminatoria y, consecuentemente, inconstitucional.

La «remuneración mínima» que busca introducir la «Ley de la Nueva Empresa» resulta perjudicial para el trabajador sujeto a ella, pues este perdería - al trasladarse a este nuevo régimen - un mecanismo de protección contra el desempleo como es la CTS.

La «remuneración mínima» propia de lo que sería el régimen de la «Ley de la Nueva Empresa» tiene como base de cálculo a la remuneración que el trabajador percibe por hora trabajada, la cual puede ser menor a la remuneración mínima del sistema genérico.

No cabe un trato diferenciado en materia de seguridad social para los trabajadores insertos en el régimen de la «Ley de la Nueva Empresa». Lo correcto es que estos ingresen como afiliados regulares de los sistemas previsionales y de salud, pudiendo el Estado subsidiarlos en parte.

En general, consideramos que no existe un sustento objetivo que valide la introducción del régimen propuesto y sus tratos diferenciados a nuestro sistema jurídico, motivo por el cual este resulta inconstitucional.

UNA VISIÓN

PONDERADA DE

LA LEGISLACIÓN

LABORAL:

COMENTARIOS AL

RÉGIMEN MYPEY

A LA PROPUESTA

$D E$ «LEY DE LA

NUEVA EMPRESA»

A WEIGHTED VIEW

OF LABOR LAW:

COMMENTARIES

ON THE MSE

REGIME AND

THE PROPOSAL

"LAW OF NEW

ENTERPRISE" 